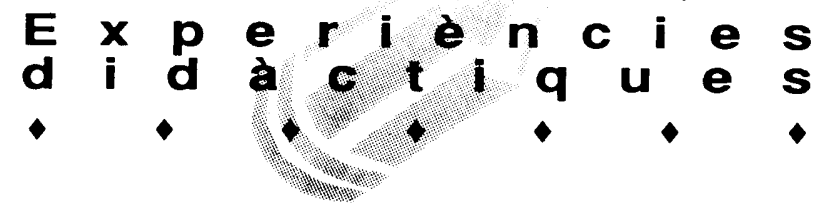

\title{
L'APRENENTATGE DE LA LLENGUA ANGLESA A PARTIR DELS 8 ANYS
}

Seguint la nova ordenació de L'Educació Primària, on s'introdueix als 8 anys l'aprenentatge d'una altra llengua, $i$ com que durant aquest curs ens trobàvem dos especialistes d'anglès a 3er d'E.G.B, ens vam plantejar iniciar a l'escola aquesta experiència per dues raons:

- En primer lloc el treball en equip és sempre més gratificant que quan es fa de forma individual, al mateix temps que s'aprofita molt més l'experiència personal de cadascú. Així, a partir dels objectius generals trets del disseny curricular d'Ensenyament Primari, vam elaborar les unitats de programació que poguéssim preparar i portar a terme de forma global dins l'horari escolar. En la programació hem procurat incloure conceptes, procediments ivalors de caràcterformatiu i prou motivadors per als nens, aixi com augmentar l'interès cap a altres llengües i cultures, donant, però, sempre prioritat al desenvolupament dels aspectes comunicatius ifuncionals de la llengua oral.

- En segon lloc, per a nosaltres era la primera vegada que iniciàvem aquesta experiència amb nens d'aquesta edat, i per tant ens ho vam prendre amb molta il. lusió i amb la intenció d'apropar els nens a la llengua anglesa a partir del seu entorn i de les necessitats que tenen de comunicar-se.

\section{Objectius generals}

Ens hembasat en els objectius del disseny curricular d'Educació Primària per a l'aprenentatge precoç de l'anglès. L'objectiu primordial és afavorir la comunicació $i$ totes les destreses que la fan possible, de forma ben delimitada per als interessos del nens en cada moment: parlar d'ells mateixos, del que els agrada, de les seves activitats de lleure, dels seus programes favorits de T.V., del seu entorn més proper, dels seus amics, de les festes, és a dir, de tot allò que forma la part més important de la seva vida.

Els objectius generals són els següents:

- Introduir la llengua de forma oral preferentment, almenys durant el primer any, tan pelque fa a la comprensió com a l'expressió. Es poden també anar introduint gradualment algunes paraules del vocabulari treballat $i$ frases senzilles escrites que responguin a la necessitat dels nens i els facin notar la diferència entre la forma oral i l'escrita.

- Ajudar els nens perquè al final de l'etapa 6-12 siguin capaços de mantenir una petita conversa en anglès $i$ entendre textos referits a experiències concretes de la seva vida diària.Conèixer i reproduir amb bona

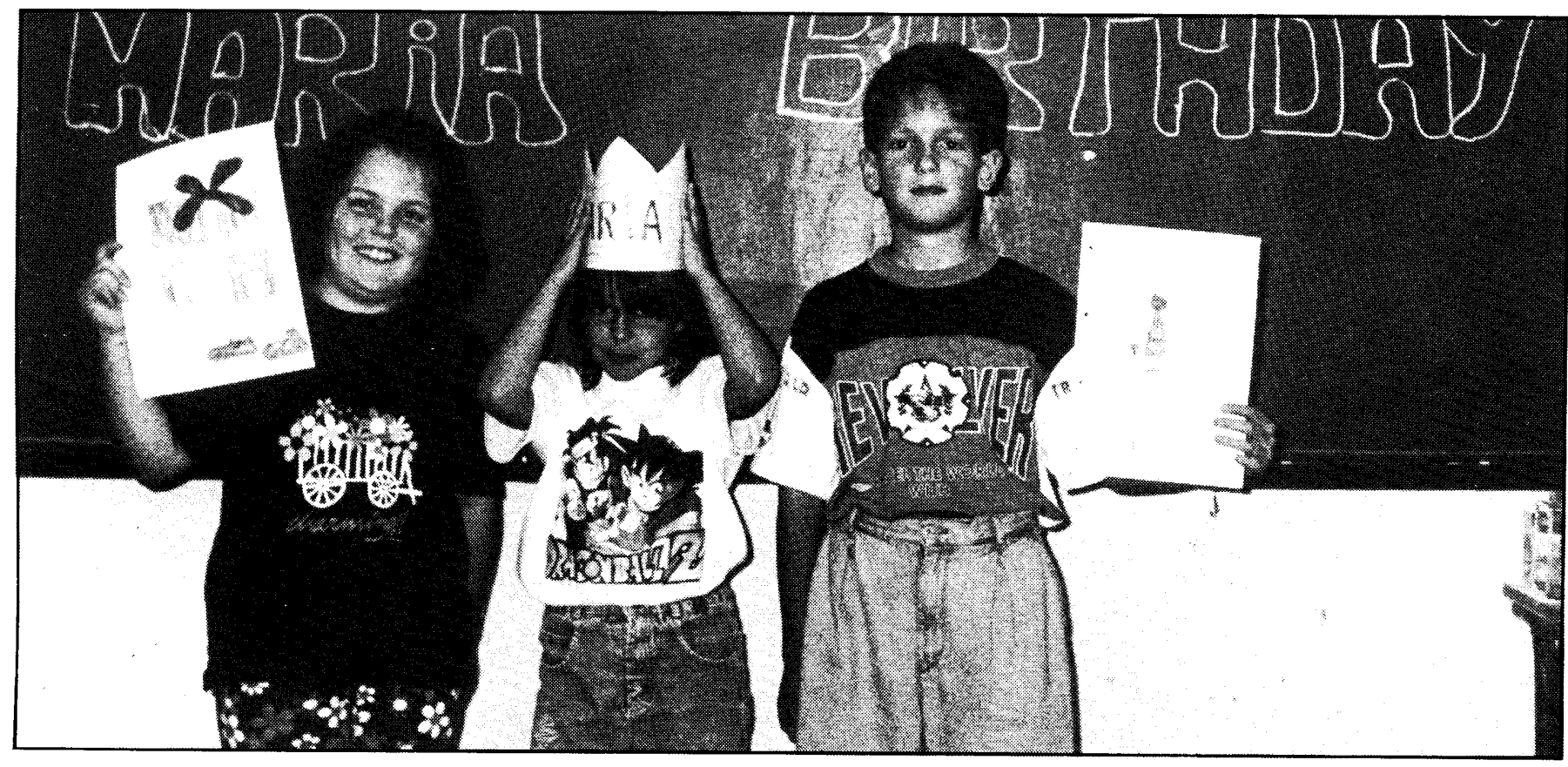




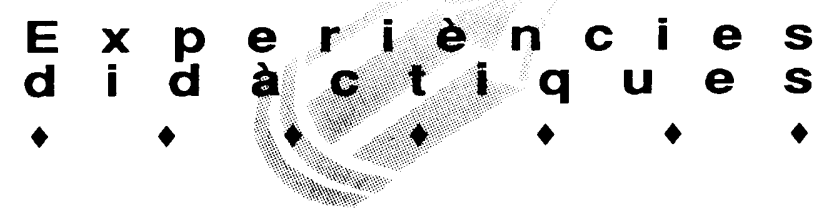

pronunciació el vocabulari pròxim a la seva realitat.

- Utilitzar materials (dibuixos, làmines, murals, franel.logrames) i estratègies adients que ajudin el nen a interpretar l'anglès directament sense necessitat de recórrer a la traducció mental, creant així una situació favorable per a l'aprenentatge.

- Crear situacions vives $i$ que responguin a la vida, coneixements i interessos del nen.

- Proposar activitats motivadores per tal de mantenir l'interès de l'infant $\mathrm{i}$ fer que psicològicament visqui la situació.

- Involucrar els nens en diferents situacions de llengua oral, si bé només ens proposàrem que en reprodueixin una petita part. L'ús de diàlegs curts per representar (cançons, contes, historietes i petits poemes) seran molt útils.

- Aprendre la pronunciació i les estructures morfosintàctiques $i$ lèxiques de manera espontània $i$ natural, reforçant-les mitjançant la repetició, deixant, però, un marge de creació per a aquells alumnes psicològicament més madurs o amb més facilitat per a la llengua.

- Integrar la classe d'anglès dins el currículum general de l'escola. Fer que sigui una eina més per revisar i reforçar aspectes educatius, socials i d'aprenentatge treballats en altres àrees.

- Desenvolupar les capacitats individuals del nen per aprendre llengües.

A continuació es pot veure desenvolupada una de las unitats de programació:

Unitat de programacio: Greetings and introduising yourself.

Temporització:5 sessions de mitja hora (primer trimestre del cicle mitjà).

\section{Continguts de procediments}

- Interpretació de la salutació: "Hello" i de: «My name is...". name?

- Reproducció oral de la pregunta: “What's your

- Presentació i memorització dels deu primers nombres. classe:

- Interpretació adequada de les ordres habituals de

- stand up

- sit down

- go to the blackboard

- open the door

- go back to your seat

- open your book

- close your book

- be quiet

- stop

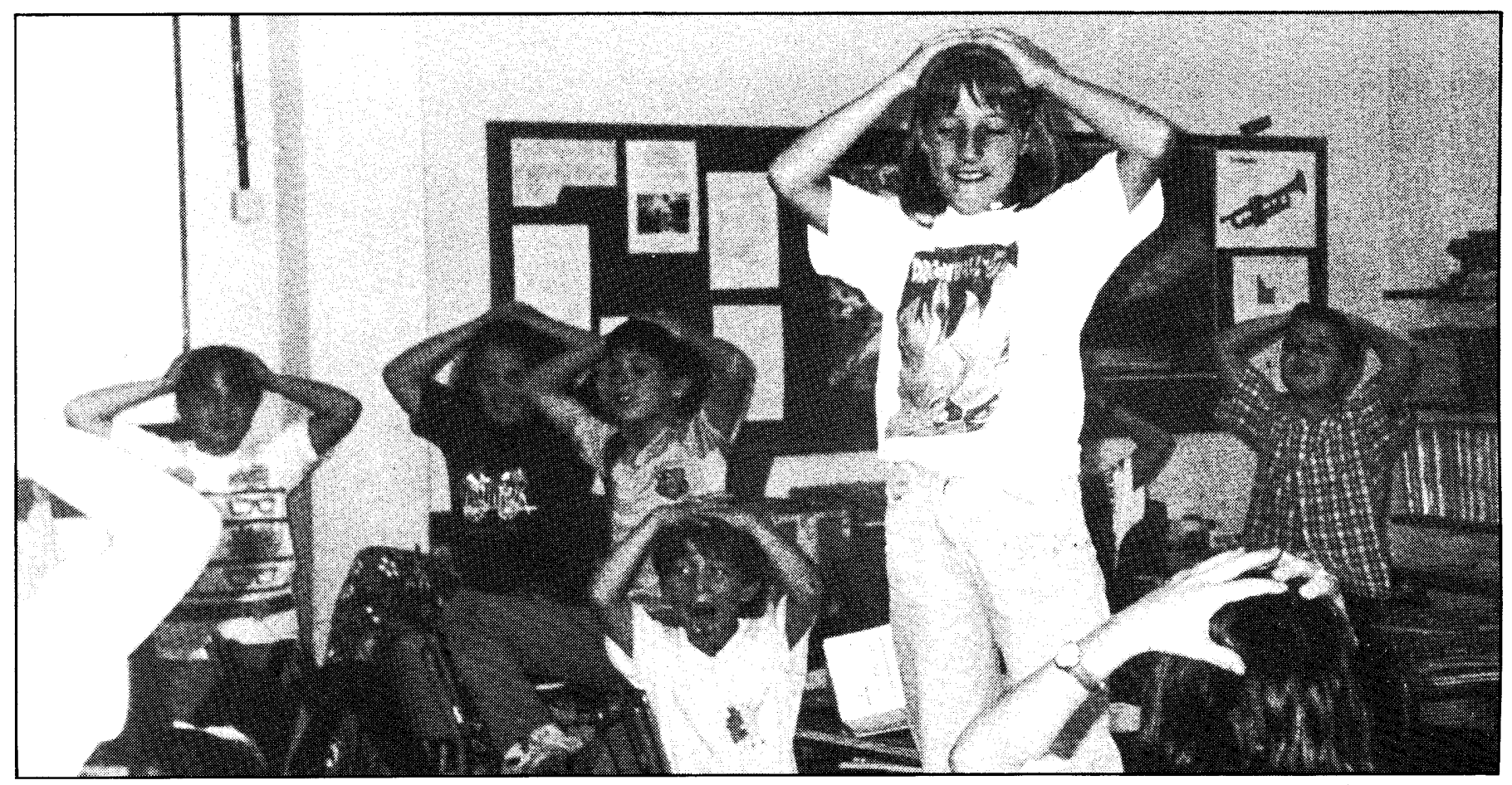




\section{$\frac{E}{9} \times x^{8}:$}

- Interpretació adequada de les ordres per realitzar diferents manualitats: take, cut out, write, put it on, glue, colour,...

\section{Continguts de fets $\mathbf{i}$ conceptes}

- Salutació.

- Identificació personal.

- Nombres del 0 al 10.

- Ordres d'accions habituals de classe.

- Ordres per a la realització d'activitats manuals.

\section{Continguts d'actituds, valors i normes}

- Actitud positiva envers la llengua anglesa.

- Interès per participar en totes les activitats de classe.

- Valoració dels jocs, cançons i altres activitats com a part de l'aprenentatge.

\section{Objectius didàctics}

- Contestar a la salutació: «Hello" i al comiat: “Good bye".

- Entendre iformular la pregunta: "What's your name?"

- Distingir la pregunta: "What's your name" i la resposta: "My name is..."

- Aprendre i reconèixer els nombres de l'1 al 10

- Identificar i representar les ordres de classe treballades.

- Participar activament en el joc i les cançons.

\section{Activitats d'aprenentatge}

- Greeting the pupils and introduising oneself.

- Asking somebody's name.

- Let's make a badge. Cada alumne disposa d'un tros de cartolina on dibuixa i retalla (seguint les ordres donades en anglès) la figura d'una cosa que li agrada (núvol, flor, triangle, rodona...) i escriu el seu nom dins. Poden inventar-se noms imaginaris i a continuació jugar uns minuts fent servir l'estructura: "What's your name" i "my name is ..."

- Show the number I say. Després d'introduir els nombres podem fer aquesta activitat, que consisteix a dir el nom del nombre que el mestre o un alumne ensenya en un cartellet, que prèviament hauran confegit els alumnes.

- Let's make groups. És un joc que consisteix a fer grups d'alumnes segons el nombre indicat. Els alumnes roden per la classe al compàs d'una música i quan para la música el mestre o un alumne diu: Make groups of five, four, two... Els alumnes que no aconsegueixen formar part de cap grup, queden eliminats.

- Bingo. Els alumnes escriuen sobre un cartonet dividit en sis caselles, sis nombres de l' 1 al 10 a escollir A continuació es farà un joc de bingo per veure quin alumne aconseguix fer Bingo o Línia

- What's our favorite number? Cada alumne escull un nombre i l'escriu. Després el mestre pregunta: “What's your favorite number? i cada alumne respon i a la pissarra es van anotant els vots que treu cadascun. Al final es fa recompte i es veu quin ha estat el nombre més escollit $i$, per tant, el favorit.

\section{Song: Ten little indians}

One little, two little, three little indians.

Four little, five little, six little indians.

Seven little, eight little, nine little indians.

Ten little indian boys.

\section{Activitats d'avaluació}

- Presentació personal.

- Joc: Simon says...

- Per grups cantar un tros de la cançó presentada, seguint una ronda.

- Reproduir els nombres que el mestre indiqui.

Salvador Moreno Bravo i $M^{a}$ del Carme Figuerola Bardolet Mestres del Cicle Mitjà Col.legi Públic de Pràctiques. Tarragona. 